\title{
The influence of cheerleading exercises on the demonstration of strength and endurance of 15-17-year-olds girls
}

\author{
Krivoruchko N.V. ${ }^{1 \mathrm{ABCDE}}$, Masliak I.P. ${ }^{1 \mathrm{ABCDE}}$, Bala T.M. ${ }^{1 \mathrm{ABCDE}}$, Skripka I.N. ${ }^{2 \mathrm{ABCDE}}$, Honcharenko V.I. ${ }^{2 \mathrm{ABCDE}}$ \\ ${ }^{1}$ Department of Theory and Methodology of Physical Education, Kharkiv State Academy of Physical Culture, \\ Ukraine \\ ${ }^{2}$ Department of Theory and Methodology of Sport, Sumy State Pedagogical University named after A. S. Makarenka, \\ Ukraine
}

Authors' Contribution: A - Study design; B - Data collection; C - Statistical analysis; D - Manuscript Preparation; E - Funds Collection.

\begin{abstract}
Purpose: $\quad$ to define dynamics of indicators of endurance and strength development of 15-17-year-olds girl-students after application of cheerleading exercises.

Material: $\quad$ The study involved students of I-III courses of a nonsports profile ( $n=385$, age $-15-17$ years). The level of strength and endurance development was determined by tests. In the educational process of the student of experimental groups was introduced cheerleading (basic motor actions by hands and legs, jump elements, stunt, dancing combinations). Duration of a class was 1 hour 30 minutes.

Results: $\quad$ it is determined positive dynamics of development of indicators of strength and endurance after application of exercises of cheerleading. The most significant growth was observed in indicators of muscle strength of hands. The most significant growth in results of the level of strength development was observed in girls aged 15 years. Priority for students of 15-17-year-olds is a complex development of physical qualities.

Conclusions: application in the educational process of elements of cheerleading influenced positively on the level of strength and endurance development of girls of 15-17-year-olds. The most significant growth of indicators of strength was determined in 15-year-old girl students, indicators of endurance were determined in 16-year-old girl students.

Keywords: physical qualities, students, physical training, cheerleading elements.
\end{abstract}

\section{Introduction}

Modern conditions of life set high requirements to the health condition, vitality and activity of the population, a different age. However, there is a tendency to decline the indicators of health and decrease in the level of motor fitness of the young population of Ukraine. It is determined «low» level of physical development of students $[1,2]$; «average» level of functioning of the cardiovascular system of primary and elementary school children [3, 4]; «average» and «below average» of 7-8 forms school children [5]. It is determined that the third part of high school children (35-38\%) have a deviation in health condition [6].

The negative tendency concerning the development of motor qualities is proved by the researches of the level of physical fitness of 17-19-year-olds girl students [7, 8]. It is determined that $35,4 \%$ of students have the average level of physical fitness, $28,4 \%$ - below the average, $8,6 \%-$ low, $22,9 \%$ - above the average, $4,7 \%$ - the high level. It is determined that pupils of 5-6 forms under the influence of cheerleading exercises demonstrated «below the average» level of endurance development and «average» level of strength development [9]. It is observed the significant decrease in the level of development of the main physical qualities in comparison with the previous generation of motor actions abilities of high school pupils [10].

The important place among physical qualities is taken by strength and endurance that reflect important indicators of the functional condition of the locomotor system of the person. The analysis of scientific data demonstrates that priority means in health improvement of youth and (C) Krivoruchko N.V., Masliak I.P., Bala T.M., Skripka I.N.,

Honcharenko V.I., 2018

doi:10.15561/20755279.2018.0303 increase the level of physical fitness is the performance of physical exercises and optimum physical activity. Actually, physical health of students is an integrated indicator of their vitality $[11,12]$. It includes physical development, physical fitness, physical condition. It is the content of physical culture which is an integral part of the general culture of society. In other research [13] the attention is focused on the fact that physical exercises provoke corporal joy, satisfaction, and pleasure. According to the other data [14], physical training can realistically, reasonably and safely promote a solution to the overweight problem and obesity in children. At the same time, it is desirable to attract all children to physical activity both within physical training classes, and after it. The east practices [15] also promote positive dynamics of indicators in exchange processes (that is the maximum consumption of oxygen, VO2max) and arterial blood pressure of students.

It is known that modern students aren't satisfied by the traditional approach to after physical training studies [16, 17]. They are interested in innovative means, approaches, and forms of physical activity classes. Therefore there is a sense in the optimization of physical training process [18].

It was found out a significant amount of the researches devoted to search and introduction into physical training process the various traditional and nonconventional means, forms and approaches. All of them are directed to increase the level of functional and motor action readiness of the different age contingent. Other authors [19] suggest to include sports games into the classes content of secondary school. This type of motor action activity influences on the functional and motor action readiness 
of pupils identical with others games-based sport. The effective means of flexibility and coordination abilities development of students are east practices [20]. The application of power exercises in the physical training process influences positively on the level of physical fitness and functionality of students [21, 22]. It is also determined that introduction of aerobics into the teaching and educational process of physical training influenced positively on the development of physical qualities [23, 24].

At the same time, several types of research were directed into the study of teachers' activity in the application of innovative approaches into the educational institutions. It was determined the insufficient level of their introduction into the educational process in the research of innovative forms and methods of study [25]. The significant quantity of teachers $(62 \%)$ introduces the differentiated study, fitness, aerobics, Internet technologies and intersubject communications into the educational process [26]. However, in all variety of pedagogical innovations, this process was found out the insufficient readiness of teachers to this activity. Therefore it is necessary to hold special scientifically-based events devoted to the continuous professional development of physical culture teachers $[27,28]$. It will expand their opportunities concerning the introduction of the innovative content.

It is defined that 15-17-year-olds students have inclinations to the new non-conventional types of motor action activity $[16,17]$. The cheerleading contains the wide range of various intensive motor actions which include elements of choreography, acrobatics, gymnastics, sport and national dances [29-31]. It is differed by visual appeal, variable influence, dynamic, availability of the application. In other researches positive changes in indicators of physical development [1] and physical efficiency [32] of 15-17-year-olds students under the influence of cheerleading exercises.

The analysis of scientific and methodical literature revealed the existence of the insignificant quantity of the researches devoted to studying of cheerleading influence on the young organism. It was determined the positive influence of cheerleading on the development of motor memory and on coordinate motor actions of preschool age children $[33,34]$. It was revealed that the cheerleading carries out the significant influence on the development of physical qualities of primary school age children [35]. It is proved the positive influence of cheerleading exercises on the level of strength and endurance development in secondary school pupils [9]. Introduction of a reasonable technique of occupations of a cheer dance on out-of-class occupations allows students to improve their physical condition [36]. It is observed in other researches [37, 38] that in cheerleading athletes have positive dynamics of indicators of the level of coordination development, high-speed and power and high-speed abilities, flexibility, and strength. The question of cheerleading influence on the physical qualities manifestation of 15-17-year-olds students is insufficiently studied.
The hypothesis of the research presupposed that the innovative component of the physical training content in the form of cheerleading exercises has to be reflected in the indicators of strength and endurance of the main muscle groups of 15-17-year-olds girls.

The purpose of the research is to define dynamics of strength and endurance indicators of 15-17-year-olds girlstudents after application of cheerleading exercises.

\section{Material and methods}

Participants. The study involved students of I-III courses of a nonsports profile $(n=385$, age $-15-17$ years). All participants signed the informed consent to participation in a research.

\section{Organization of a research.}

Researches were conducted at Teacher Training College of Kharkiv Humanitarian Pedagogical Institute. It was created 3 control and 3 experimental groups: I group - girl-students of the I course, II group - girl-students of the II course, III group - girl-students of the III course. All girl-students belong to the main and preparatory medical groups. During the experiment, the educational process of girl-students of control groups was based on the typical motor action activity for these educational institutions (track and field, volleyball, basketball). These classes included theoretical, technical and tactical training. The cheerleading was introduced into the educational process of girl-students of the experimental groups (basic motor actions by hands and legs, ump elements, stunt, dancing combinations). Duration of a class was 1 hour 30 minutes. The study was performed in several stages: 1st stage study to the basic motor actions, 2nd stage - the study of basic jumps, $3 \mathrm{rd}$ - the study of stunt and pyramids, 4 th $-\mathrm{a}$ combination of stunts of the studied elements. The study was based on the principle from simple to difficult.

The level of endurance development was defined according to the results of $2000 \mathrm{~m}$ run ( $\mathrm{sec}$ ). The level of strength development was determined by indicators of pressing ups in lying position (quantity of times), torso rising from lying position into sitting one in 1 minute (quantity of times), advanced single leg jumps (m), hand dynamometry $(\mathrm{kg})$ forward. The $\ll 3$ advanced single leg jumps» test was performed in standing position. It consists in a continuous performance of 3 advanced single leg jumps. The distance which was overcome by the student in meters was a result. The received results were compared to a standard scale (tab. 1) [39] and were estimated by a certain number of points.

Statistical analysis:

Materials of the research were processed by Excel. It was calculated: arithmetic mean $(\bar{X})$ - for the characteristic of population by separate parameters; standard mistake of mean (m) - for definition of arithmetic mean deviation from the corresponding parameters of population; significance of differences ( $p$ ) - with the purpose to determine the level of changes of average means of the studied parameters after the experiment by means of Student t-test ( $t$ ) at the significance level $\mathrm{p}>0,05$. 


\section{Results}

The received data concerning strength development before experiment testify to absence of significant differences between data of students of the experimental and the control groups $(\mathrm{p}>0,05)$. The comparison of the received results with a standard scale [39] demonstrated that the strength development level of I-III courses students corresponding to the grade «sufficient» (tab. 2).

The data after the experiment (fig. 1) determined that all indicators of strength development level in girl-students of the experimental groups considerably and significantly improved $(\mathrm{p}<0,05-0,001)$. The most essential changes were in indicators of pressing ups in lying position. The most significant growth in results of strength development level is observed in 15 year-olds girls.

Indicators of girl-students of the control groups also improved a little, but less essential and non-significant $(p>0,05)$. Comparison of the received data after the experiment with estimated standards demonstrated the increase in grade on one point in the following cases: by results of pressing ups in lying position in students of II group (from 2 points on 3 points); by results of torso rising from lying position into sitting one in students of III group (from 2 points on 3 points); by results of single leg jumps in I and II age groups (from 1 point on 2 points); by results of hand dynamometry in students of III groups (from 3 on 4 points). Other grades were left without changes in spite of considerable and significant

Table 1. Standardizing estimations

\begin{tabular}{|c|c|c|c|c|c|}
\hline \multirow[b]{2}{*}{ Age, years } & \multicolumn{5}{|c|}{ Estimation, points } \\
\hline & 5 & 4 & 3 & 2 & 1 \\
\hline & \multicolumn{5}{|c|}{ Standardizing estimations of pressing ups in lying position (quantity of times) } \\
\hline 15 & 19 & 16 & 12 & 8 & 5 \\
\hline 16 & 20 & 16 & 12 & 8 & 5 \\
\hline \multirow[t]{2}{*}{17} & 22 & 17 & 13 & 9 & 5 \\
\hline & \multicolumn{5}{|c|}{ Standardizing estimations of torso rising from lying position into sitting one (quantity of times) } \\
\hline 15 & 43 & 38 & 33 & 29 & 24 \\
\hline 16 & 44 & 39 & 35 & 30 & 25 \\
\hline \multirow[t]{2}{*}{17} & 45 & 40 & 35 & 31 & 26 \\
\hline & \multicolumn{5}{|c|}{ Standardizing estimations of 3 advanced single leg jumps (m) } \\
\hline 15 & 5,80 & 5,30 & 4,50 & 4,25 & 3,70 \\
\hline 16 & 6,00 & 5,50 & 4,70 & 4,30 & 3,80 \\
\hline \multirow[t]{2}{*}{17} & 6,10 & 5,60 & 4,90 & 4,35 & 3,80 \\
\hline & \multicolumn{5}{|c|}{ Standardizing estimations of $\mathbf{2 0 0 0} \mathrm{m}$ run (min, sec) } \\
\hline \multirow[t]{3}{*}{$15-17$} & 9.40 & 10.30 & 11.20 & 12.10 & \\
\hline & \multicolumn{5}{|c|}{ Standardizing estimations of hand dynamometry (kg) } \\
\hline & Sufficient & Satisfactory & Good & Excellent & \\
\hline 15 & 18 and less & 19 & 24 & 29 & \\
\hline $16-17$ & 24 and less & 25 & 30 & 35 & \\
\hline
\end{tabular}

Table 2. Estimation of the strength development level of girl-students before the experiment

\begin{tabular}{|c|c|c|c|}
\hline \multirow[b]{2}{*}{ Indicators } & I group & II group & III group \\
\hline & \multicolumn{3}{|c|}{$\begin{array}{l}\text { Level of strength development } \\
\text { Experimental group }\end{array}$} \\
\hline $\begin{array}{l}\text { pressing ups in lying position (quantity of } \\
\text { times) }\end{array}$ & «average» & «below average» & «low» \\
\hline $\begin{array}{l}\text { torso rising from lying position into sitting } \\
\text { one (quantity of times) }\end{array}$ & «average» & «average» & «below average» \\
\hline 3 advanced single leg jumps (m) & «low» & «low» & «low» \\
\hline \multirow[t]{2}{*}{ hand dynamometry (kg) } & «above average» & «average» & «average» \\
\hline & Control group & & \\
\hline $\begin{array}{l}\text { pressing ups in lying position (quantity of } \\
\text { times) }\end{array}$ & «average» & «below average» & «low» \\
\hline $\begin{array}{l}\text { torso rising from lying position into sitting } \\
\text { one (quantity of times) }\end{array}$ & «average» & «average» & «below average» \\
\hline 3 advanced single leg jumps (m) & «low» & «low» & «low» \\
\hline hand dynamometry (kg) & «above average» & «average» & «average» \\
\hline
\end{tabular}


improvement.

The similar comparison of results of girl-students of control groups wasn't found out changes according to the presented rating scale. The exception indicators are hand dynamometry where grade in students of III groups increased from 3 on 4 points.

The analysis of primary results of endurance demonstration (2000 m run), testify to identity of the experimental and the control groups $(p>0,05)$. The comparison of data with estimated criteria [39] demonstrated «low» level of endurance development in all groups (tab. 3).

The analysis of data after the experiment demonstrated that indicators of endurance development in girl-students considerably and significant improved $(p<0,001)$. The most significant growth of indicators is observed in 16-year-old girls (fig. 2). The comparison of results with the standards [39], demonstrated changes according to the rating scale. Therefore the level of endurance development is «low».

The subordinate data of control groups determined that they improved a little. These changes in students of II and III groups are significant $(p<0,05-0,01)$. Thus, girl-students of I group improved results in 22 seconds; II - in 42 seconds; III - in 46 seconds. It is also determined considerable and significant domination of results of girlstudents of the experimental groups $(p<0,001)$ (fig. 3). The comparison of subordinate indicators of the control groups with standards [39] didn't demonstrate changes according to the presented rating scale.

\section{Discussion}

The result of generalization of the experimental data and the theoretical analysis we revealed the effective

Table 3. Estimation of endurance development level in girl-students before the experiment

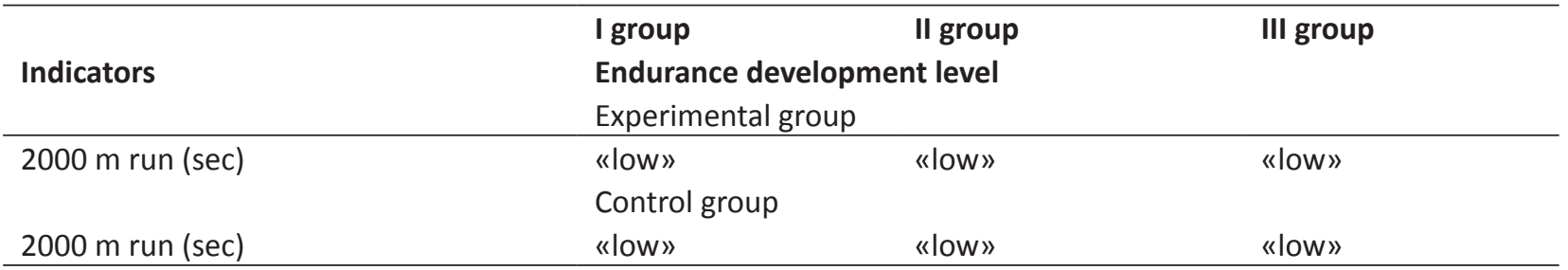

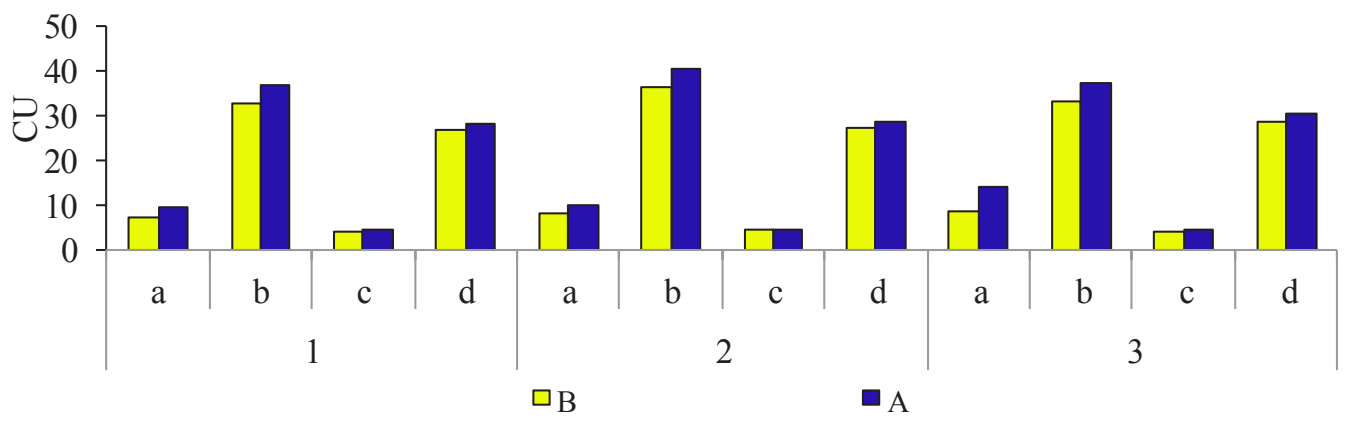

Fig. 1. Indicators of strength development level of girl-students of the experimental groups before and after the experiment: $a$ - pressing ups in lying position (quantity of times); $b$ - torso rising from lying position into sitting one (quantity of times); c - 3 single leg jumps (m); $d$ - hand dynamometry (kg); CU - conventional units; B - before the experiment; $\mathrm{A}$ - after the experiment; 1, 2, 3-numbers of groups.

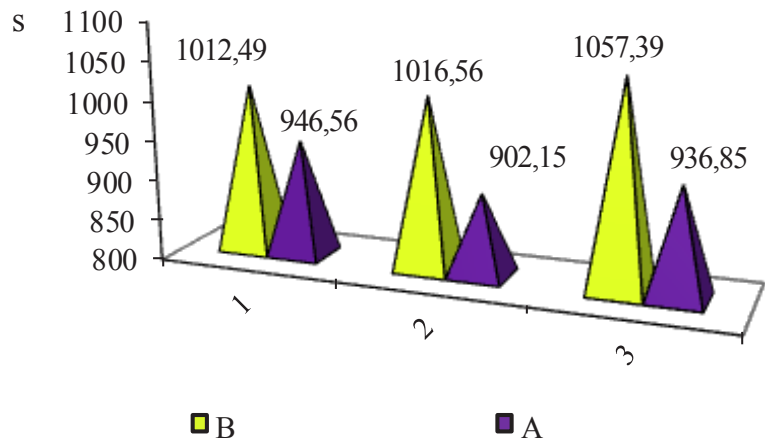

Fig. 2. Indicators of the endurance development level of girl-students of the experimental groups before and after the experiment. $\mathrm{s}$ - seconds; $\mathrm{B}$ - before the experiment; $\mathrm{A}$ - after the experiment; 1, 2, 3-numbers of groups. 


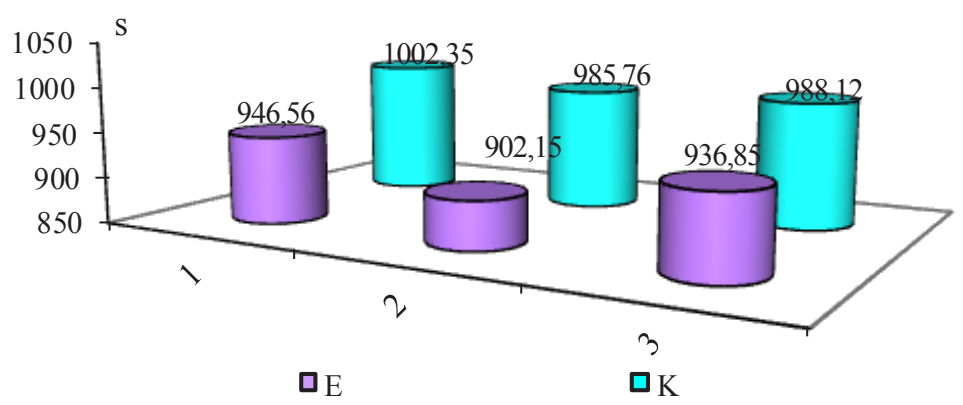

Fig. 3. Indicators of endurance manifestation of girl-students of the experimental and control groups after the experiment. s-seconds; $\mathrm{B}$ - experimental groups; $\mathrm{K}$ - control groups; 1 , 2, 3-numbers of groups.

influence of cheerleading exercises on the separate studied indicators of students.

The introduction of cheerleading in process of physical training of 15-17 year-olds students supplements the existing data concerning the application of cheerleading in educational and training process of the young generation.

In earlier researches was defined the positive dynamics of indicators of strength and endurance development level in pupils of 5-6 forms under the influence of cheerleading exercises [9]. Authors determined that exercise of cheerleading had an essential influence on a growth of legs strength indicators. According to our researches, the growth in strength indicators of students was more essential. It is mostly observed in indicators of muscles hands strength. It is confirmed by other data [39-41]. Authors note that the age of 15-17 year is sensitive for development of strength and endurance. It is determined the progressive growth of noted indicators during this period.

Other authors confirm [37, 38] that cheerleading athletes have positive dynamics in indicators of the development level of coordination, high-speed abilities, flexibility, and strength. The technology of work with implement was improved. The optimum correlation of training means was experimentally determined. It allows considerably increase the level of special fitness and increase of technical skills of cheerleaders. It was also defined [36] positive influence on the physical development and motor action activity of students of the introduction of one of the cheerleading types - a cheer dance on extracurricular classes (sections). As distinguished from above-mentioned scientific works our researches are focused on the application of cheerleading in the educational process, not in sports training. Also, our researches are focused on the age of 15-17 year whereas above-mentioned works are focused on senior age group of students. It is an essential difference and significant supplement to the available researches in the field of professional cheerleading. Our received results testify to the efficiency of cheerleading application in training and educational process. In other researches [35] was defined a growth of integrated indicator of physical fitness of 1-4 forms pupils. It was in result of attended the extra sports section of cheerleading. The most significant growth of physical qualities is observed in indicators of flexibility, dexterity and strength of certain sets of muscles. However unlike these researches, we have also investigated strength of muscles of abdominal press and strength of hand. It gives the possibility to estimate more deeply the influence of cheerleading system exercises.

According to results of other research [33] the cheerleading influences positively on the development of motor action memory and on coordinate of motor actions of preschool age children. We agree with the fact that mentioned positive changes are important for preschool age children [34]. The priority for 15-17 year-olds students is a complex development of physical qualities.

Proceeding from the above the most significant growth of students' physical qualities is under the influence of cheerleading exercises.

Our results supply data concerning the positive influence of cheerleading exercises on the development of motor action qualities [9]. It also expands the data concerning the influence of cheerleading on indicators of physical development and physical efficiency of college students $[1,32,36]$. We definitely revealed the most susceptible cheerleading exercises for development of strength abilities of college students. We found out the age periods of expedient application of cheerleading as to a development tool of strength and endurance. It is proved that the cheerleading can be applied as an alternative type of motor action activity for the development of strength and endurance of 15-17 year-olds students.

\section{Conclusions}

Application of cheerleading elements in the educational process influenced positively on the level of strength and endurance development of girl-students from Teacher Training College. Thus, it is revealed the significant increase in muscle strength of girdle of superior extremity, abdominal press, and legs after application of cheerleading. Above-mentioned changes testify the increase in the level of development of all forms of demonstration of strength abilities. It was defined the potential decrease of time for overcoming a distance which is stipulated the increase in intramuscular and intermuscular coordination, work productivity of cardiovascular and respiratory systems. It is also confirmed the development of general endurance.

Above-mentioned changes testify that the applied system of cheerleading exercises is effective means of the 
increase in the level of physical qualities development.

Thus, our researches allow recommending to physical training teachers of colleges to complete the content of classes with cheerleading exercises.

\section{Acknowledgements}

The research was carried out in accordance with the Thematic Plan of the Kharkov State Academy of Physical
Culture on the topic «Improving the process of physical education in educational institutions of various profiles» for years 2016-2020. (State Registration Number 011U00754).

\section{Conflicts of interest}

The authors declare that there is no conflict of interests.

\section{References:}

1. Jagiełło M, Iermakov SS, Nowiński M. Differentiation of the somatic composition of students physical education specialising in various sports. Arch Budo Sci Martial Art Extreme Sport, 2017;13:63-70.

2. Bashavets N. Current features of physical training of university students and recommendations for its improvement. Science and Education, 2016(4):105-111.

3. Kuzmenko I. Investigation of the cardiovascular system of schoolchildren aged 13-14 years. Slobozhanskyi herald of science and sport, 2017; 6(62): 51-53.

4. Doroshenko EY, Svatyev AV, Iermakov SS, Jagiełło W. The use of cardio training facilities in training 7-9 year old judo athletes. Arch Budo Sci Martial Art Extreme Sport, 2017; 13:165-172.

5. Mameshina M. Condition of physical health of pupils of the 7th-8th classes of the comprehensive school. Slobozhanskyi herald of science and sport, 2016; 5(55): 47-52. doi:10.15391/ snsv.2016-5

6. Zakhozhij V, Dikij O. Health Status and Functional Capacities of the Organism Seniors. Fizichne vikhovannia, sport i kul'tura zdorov'ia u suchasnomu suspil'stvi, 2016; 4(36): 60-66. (in Ukrainian)

7. Samokish I, Bosenko A, Klimenko O. Physical readiness as a criterion for evaluating the functionality of the university students in physical education. Pedagogichni nauki: teoriia, istoriia, innovacijni tekhnologii, 2016;3(57):269-275. (in Ukrainian)

8. Kriventsova I, Pashkevych S, Iermakov S, Bartík P, Michal J, Nosko M, Yermakova T. Fitness - aerobic training of 15 - 17 years' age girl students, who have significant risk of deviations in backbone functional state. Journal of Human Sport and Exercise, 2017;12(4), 1289-1297. doi:10.14198/ jhse.2017.124.15

9. Bala T. Change in the level of strength and endurance development of 5-6 grades pupils under cheerleading exercises influence. Slobozhanskyi herald of science and sport, 2015;3:14-18.

10.Gajvolia R. Development of Motive Internalss of Students of Senior Classes by Facilities of Physical Education in Extracurricular Time. Molodizhnij naukovij visnik Skhidnoievropejs'kogo nacional'nogo universitetu imeni Lesi Ukrainki, 2014;13:41-45. (in Ukrainian)

11.Ihnatenko S. Forming students' motivation to self-guided physical training. Science and Education. 2016(4):125-130.

12. Romanenko V, Podrigalo L, Iermakov S, Rovnaya O, Tolstoplet E, Tropin Y, Goloha V. Functional state of martial arts athletes during implementation process of controlled activity-comparative analysis. Physical Activity Review, 2018; 6: 87-93. doi: doi:10.16926/par.2018.06.12

13.Wellard I. Reflective pleasure body: the study of bodily experiences in the context of sport and physical activity. Sport, Education and Society, 2011;17(1):21-33.

14.Keyl L, Harris D. "Every child (each size) is set to" in physical education! The role of physical education in childhood obesity. Sport, Education and Society, 2013; 18(4): 433-452.

15.Chu P, Gotink RA, Yeh GY, Goldie SJ, Hunink MGM. The effectiveness of yoga in modifying risk factors for cardiovascular disease and metabolic syndrome: A systematic review and meta-analysis of randomized controlled trials. European Journal of Preventive Cardiology. 2016;23(3):291307. doi:10.1177/2047487314562741

16.Azhippo OIu, Krivoruchko NV. To question of increase in interest of students to physical training classes. II Ukrainian scientific and practical conference "Current Problems of Physical Training of Different Segments of Population», Kharkiv, May 20 in 2016. Kharkiv; 2016. P. 6-11. (in Ukrainian)

17.Krivoruchko NV. Research of students relation of higher educational institution I-II accreditation level to physical training classes. Slobozhans'kij naukovo-sportivnij visnik, 2011; 2:25-28. (in Ukrainian).

18.Krivoruchko NV, Masliak IP. Ways of improving physical development and physical preparedness of the young generation. Naukovij chasopis Nacional'nogo pedagogichnogo universitetu imeni M.P.Dragomanova, 2016;11(81):56-60. (in Ukrainian)

19.Katzmarzyk PT, Denstel KD, Beals K, Bolling C, Wright C, Crouter SE, et al. Results From the United States of America's 2016 Report Card on Physical Activity for Children and Youth. Journal of Physical Activity \& Health. 2016;13(11):S307-S313. doi:10.1123/jpah.2016-0321

20.Tolchieva G. Improving the performance of flexibility and coordination abilities university girls-students in the process of hatha-yoga classes during the university year. Slobozhanskyi herald of science and sport, 2015; 1(45): 113118.

21.Osipov AY, Kudryavtsev MD, Iermakov SS, Jagiello W. Criteria for effective sports selection in judo schools - on example of sportsmanship's progress of young judo athletes in Russian Federation. Archives of Budo. 2017;13:179-186.

22.Osipov AY, Kudryavtsev MD, Iermakov SS, Jagiello W. Topics of doctoral and postdoctoral dissertations devoted to judo in period 2000-2016-the overall analysis of works of Russian experts. Archives of Budo. 2017;13:1-10.

23.Bondarenko O, Klischuk A. Rhythmoplastic gymnastics as a means of developing flexibility in students. Science and Education. 2016(4):117-120.

24.Drozdova K. Forming axiological attitude towards healthy lifestyle among junior schoolchildren. Science and Education. 2016(4):120-125.

25.Danylevych M, Romanchuk O, Hrybovska I, Ivanochko V. Pedagogical conditions of introduction of innovative educational technologies into the professional training of future specialists in the field of physical education and sport. Journal of Physical Education and Sport, 2017; 17(3); 11131119.

26. Maslyak IP, Mameshina MA, Zhuk VO. The state of application of innovation approaches in physical education of regional education establishments. Slobozhanskyi herald 
of science and sport, 2014;6(44):72-76. doi:10.15391/ snsv.2014-6.013

27.Braga L, Dzhons E, Baldzher S, Elliott E. Expansion of teachers opportunities to introduce innovative content in physical education through continuous professional development. Development of teachers. International Journal of Teacher Professional Development, 2017;21(2):288-306.

28.Borshchenko V. Future teachers' skills of organization and implementation of health saving activities at primary school. Science and Education. 2017(10):58-65. doi:10.24195/24144665-2017-10-7

29.Bala TM, Masliak IP. Cheerleading in physical training of schoolpupils. Kharkiv; 2014. (in Ukrainian)

30.Carrier J, McKay D. Complete cheerleading. Human Kinetics: USA; 2006

31.Chappell LR. Coaching cheerleading successfully. Human Kinetics: Canada; 2005.

32.Krivoruchko NV, Masliak IP. The dynamics of indicators of physical efficiency of students of higher education institutions of the I - II level of accreditation under the influence of cheerleading. Visnik Chernigivs'kogo nacional'nogo pedagogichnogo universitetu imeni T. G. Shevchenka, 2015;129(3):179-182. (in Ukrainian)

33.Ivanova LA, Kazakova OA, Ierusalimova MV. The formation of motor activity in children of preschool age through new healthforming technology. Koncept. 2014; 12:25-30. (in Russian)
34.Straczynska A, Kruczynski J, Radziminska A, Weber-Rajek M, Lulinska-Kuklik E, Goch A. The positive role of kinesio taping in adjunctive therapy of static plano-valgus feet in children between the ages of 5 and 7. Baltic Journal of Health and Physical Activity. 2017;9(2):89-97.

35.Bykov EV, Tianiugina MV, Galimzianova AZ. Physiological estimation of physical qualities development of primary school age children practicing cheerleading. Russian scientific and practical conference "Youth of XXI century: potential, tendencies and prospects», Ekaterinburg, 19-20 November 2013, Ekaterinburg; 2014. P. 74-76. (in Russian)

36.Barnett LA. Flying high or crashing down: Girls' accounts of trying out for cheerleading and dance. J Adolesc Res. 2006;21(5):514-541. doi:10.1177/0743558406291687

37.Raabe J, Readdy T. A Qualitative Investigation of Need Fulfillment and Motivational Profiles in Collegiate Cheerleading. Research Quarterly for Exercise and Sport. 2016;87(1):78-88. doi:10.1080/02701367.2015.1124970

38.Bodrenkova I. Improving the technique works on the subject in cheerleading at the stage of basic specialist. Slobozhanskyi herald of science and sport, 2014;2(40):31-37.

39.Romanenko VA. Diagnostics of motor action abilities, Donetsk: DonNU; 2005. (in Russian)

40.Zilov VG, Smirnov VM. Physiology of children and teenagers. Moscow: Medical information agency; 2008. (in Russian)

41.Krucevich TIu. Theory and technique of physical training. Kiev: Olympic literature; 2008. (in Ukrainian)

\section{Information about the authors:}

Krivoruchko N.V. (Corresponding author); http://orcid.org /0000-0002-5649-5490; natika19@ukr.net;Department of Theory and Methodology of Physical Education, Kharkiv State Academy of Physical Culture; Klochkivska str. 99, Kharkiv, 61058, Ukraine.

Masliak I.P.; http://orcid.org /0000-0003-1306-0849; Department of Theory and Methodology of Physical Education, Kharkiv State Academy of Physical Culture; Klochkivska str. 99, Kharkiv, 61058, Ukraine.

Bala T.M.; http://orcid.org /0000-0002-5427-6796; Department of Theory and Methodology of Physical Education, Kharkiv State Academy of Physical Culture; Klochkivska str. 99, Kharkiv, 61058, Ukraine.

Skripka I.N.; http://orcid.org/0000-0002-4446-2122; Department of Theory and Methodology of Sport, Sumy State Pedagogical University named after A. S. Makarenka; Romenskaya str. 87, Sumy, 40002, Ukraine.

Honcharenko V.I.; http://orcid.org/0000-0002-7606-2182; Department of Theory and Methodology of Sport, Sumy State Pedagogical University named after A. S. Makarenka; Romenskaya str. 87, Sumy, 40002, Ukraine.

Cite this article as: Krivoruchko NV, Masliak IP, Bala TM, Skripka IN, Honcharenko VI. The influence of cheerleading exercises on the demonstration of strength and endurance of 15-17-year-olds girls. Physical education of students, 2018;22(3):127-133. doi:10.15561/20755279.2018.0303

The electronic version of this article is the complete one and can be found online at: http://www.sportedu.org.ua/index.php/PES/issue/archive

This is an Open Access article distributed under the terms of the Creative Commons Attribution License, which permits unrestricted use, distribution, and reproduction in any medium, provided the original work is properly cited (http://creativecommons.org/licenses/by/4.0/deed.en).

Received: 04.03.2018

Accepted: 01.04.2018; Published: 27.06.2018 